Prize Winner's lecture

JSTM (Japanese Society of Tropical Medicine)

Young Investigator Award

\title{
A SINGLE-CHAIN ANTIBODY FRAGMENT SPECIFIC FOR THE PLASMODIUM BERGHEI OOKINETE PROTEIN PBS21 CONFERS TRANSMISSION-BLOKADE IN THE MOSQUITO MIDGUT
}

\author{
SHIGETO YOSHIDA
}

Department of Medical Zoology, Jichi Medical School

Pbs21 is a protein expressed on the surface of macrogamete, zygote, ookinete and oocyst stages of the rodent malaria parasite, Plasmodium berghei, as they develop in/ on the mosquito midgut. It has been reported that anti-Pbs 21 mAbs effectively block the development of $P$. berghei ookinetes in vitro and oocysts in Anopheles stephensi mosquitoes. The antigen has thus been identified as an important target in transmission-blocking immunity and is a model for development of transmission-blocking vaccines. Ideally, transmission-blocking vaccines should induce high titre, long-lasting transmission-blocking antibodies after single immunization. However, since the vaccine candidate antigens of Pfs $25 / 28$ family are expressed by parasites in the mosquito stage but not in vertebrate host, boosting of the immune response following a natural infection has never been expected. Nonetheless the induction of transmission-blocking antibodies in patiences in combination with anti-malarial drugs could be of considerable importance to prevent the spread of the drug-resistant parasites.
To examine the properties and potential uses of a single-chain antibody fragment ( $\mathrm{scFv}$ ) for blocking transmission of malaria parasites to the mosquitoes, we have cloned and sequenced the genes encoding variable regions of the immunoglobulin heavy and light chains $\left(\mathrm{V}_{\mathrm{H}}\right.$ and $\left.\mathrm{V}_{\mathrm{L}}\right)$ of mAb 13.1. The $\mathrm{V}_{\mathrm{H}}$ and $\mathrm{V}_{\mathrm{L}}$ genes were assembled as an $\mathrm{scFv}$ gene, and expressed in a baculovirus expression system. Following purification of $13.1 \mathrm{scFv}$, Western blotting and inhibition ELISA assays confirmed that $13.1 \mathrm{scFv}$ retained the binding specificity of the parent $\mathrm{mAb} 13.1$ for Pbs21. Furthermore, $13.1 \mathrm{scFv}$ bound to the surface of $P$. berghei ookinete, and blocked oocyst development in mosquito midgut by at least $93 \%$, as assessed by oocyst counts in mosquitoes. We suggest that the $13.1 \mathrm{scFv}$ gene could be useful not only in studying for the mechanism of transmission-blockade but also in generating, by mosquito germline transformation, a model system to evaluate the production of mosquitoes refractory to malaria. 